\title{
Short Communication \\ Coexistence of treatment-related MLL cleavage and rearrangement in a child with haemophagocytic lymphohistiocytosis
}

\author{
A Ng ${ }^{* 1,2}$, PF Ravetto', GM Taylor', RF Wynn ${ }^{3}$ and OB Eden ${ }^{2}$ \\ 'Immunogenetics Laboratory, University of Manchester, Central Manchester and Manchester Children's University Hospitals Trust, Manchester, UK; \\ ${ }^{2}$ Academic Unit of Paediatric Oncology, Central Manchester and Manchester Children's University Hospitals Trust, Manchester, UK; ${ }^{3}$ Department of \\ Paediatric Haematology, Central Manchester and Manchester Children's University Hospitals Trust, Manchester, UK
}

Treatment-related acute myeloid leukaemia (t-AML) is a serious complication of topoisomerase 2 inhibitor therapy and is characterised by the presence of mixed lineage leukaemia (MLL) rearrangement. By molecular tracking, we were able to show that MLL cleavage preceded gene rearrangement by 3 months and before the clinical diagnosis of t-AML in a patient with haemophagocytic lymphohistiocytosis. This is the first report on the sequential detection of the two biomarkers in treatment-related leukaemogenesis.

British Journal of Cancer (2004) 91, 1990-1992. doi:I0.1038/sj.bjc.6602269 www.bjcancer.com

Published online 30 November 2004

(C) 2004 Cancer Research UK

Keywords: treatment-related leukaemia; MLL cleavage and rearrangement; HLH

The relationship between topoisomerase 2 (topo 2) inhibitor therapy and the pathogenesis of treatment-related acute myeloid leukaemia ( $t-A M L)$ with rearrangements of the mixed lineage leukaemia $(M L L)$ gene is now well documented (Felix, 1998; Pui and Relling, 2002). This type of t-AML tends to have a myelomonocytic/monoblastic phenotype and rearrangements of the $M L L$ gene with multiple partners. Cytogenetic analysis has revealed a median latency from primary disease to t-AML of 24 months (range 10-100 months). In addition to its clinical importance as an adverse outcome of chemotherapy, t-AML provides an opportunity to investigate the timing of the molecular events involved in the pathogenesis of this condition in relation to the administration of topo 2 inhibitor therapy. We have backtracked the molecular events from a t-AML in a child with Epstein-Barr virus (EBV)-related haemophagocytic lymphohistiocytosis (HLH).

\section{PATIENT AND METHOD}

The patient was an 18-month-old boy, diagnosed with EBV-related $\mathrm{HLH}$, and treated according to the HLH-94 protocol (Henter et al, 1997) with dexamethasone, intrathecal methotrexate and intravenous etoposide $\left(150 \mathrm{mg} \mathrm{m}^{-2}\right)$ given twice weekly in the first 2 weeks and then weekly for 5 weeks (cumulative etoposide dose: $\left.1.35 \mathrm{~g} \mathrm{~m}^{-2}\right)$. At 2 months after the start of treatment,

*Correspondence: Dr A Ng, Department of Oncology, Birmingham Children's Hospital, Steelhouse Lane, Birmingham B4 6NH, UK;

E-mail: antng@blueyonder.co.uk

Received I 5 July 2004; revised 14 October 2004; accepted 19 October 2004; published online 30 November 2004; published online 30 November 2004 the patient was in complete remission, but by the 6th month after HLH diagnosis (4 months after treatment ceased), he presented with jaw swelling and cervical lymphadenopathy. Bone marrow examination revealed $70 \%$ infiltration with myeloid blasts, confirmed by cytochemistry and immunophenotyping as monoblastic AML. There was no CNS involvement by leukaemia. Interphase cytogenetics of the bone marrow showed a chromosome 9;11 translocation (47, XY, +8, $\mathrm{t}(9 ; 11)(\mathrm{p} 22 ; \mathrm{q} 23))$. The patient received induction chemotherapy (daunorubicin, cytarabine and thioguanine) for his AML according to the MRC 10th AML trial (Stevens et al, 1998) and achieved remission. At 5 months after the diagnosis of $t-A M L$, he was successfully transplanted with non-T-cell-depleted bone marrow from an HLA-matched unrelated donor, following conditioning with cyclophosphamide and total body irradiation. He remains in complete remission 28 months posttransplantation.

We collected serial blood and bone marrow samples at the time of the patient's HLH diagnosis, and thereafter at weekly intervals for 6 weeks, and then again at 3 and 6 months. Prior approval for the study was obtained from the local research ethics committee. Genomic DNA extracted from immediately frozen samples was digested with BamH1 and analysed for etoposide-induced $M L L$ cleavage (Aplan et al, 1996) and rearrangement, using a $0.74 \mathrm{~kb}$ cDNA probe spanning the $M L L$ breakpoint cluster region (BCR). The DNA was size fractionated by $0.7 \%$ agarose gel electrophoresis, and blotted onto nylon membranes. MLL cleavage was detected, after hybridisation overnight at $60^{\circ} \mathrm{C}$ with the ${ }^{32} \mathrm{P}$ labelled $M L L$ probe, using real-time autoradiography. Panhandle PCR method (Felix and Jones, 1998) was also used to analyse the same serial blood and bone marrow samples for $M L L$ rearrangement. 


\section{RESULTS}

We detected no $M L L$ cleavage in any of the peripheral blood samples obtained up to the appearance of overt t-AML, 6 months after the diagnosis of HLH. However, a $6.7 \mathrm{~kb} M L L$ cleavage fragment, identical to that detected when we incubated the haemopoietic cell line BV173 in vitro with $10 \mu \mathrm{M}$ etoposide for $6 \mathrm{~h}$, was detected in the bone marrow (morphologically $<5 \%$ blasts and no circulating blast seen) obtained 3 months after HLH diagnosis, 1 month after the last dose of etoposide (cumulative dose: $1.35 \mathrm{~g} \mathrm{~m}^{-2}$ ) and 3 months prior to the diagnosis of overt t-AML. Analysis of Southern blots of the same BamH1digested DNA samples revealed two rearranged $M L L$ fragments $(5.6,18 \mathrm{~kb})$, in addition to the $8.3 \mathrm{~kb}$ germline $M L L$ fragment, only in the bone marrow obtained at the time of t-AML diagnosis (Figures 1 and 2). Panhandle PCR confirmed the presence of $M L L$ rearrangement and the $5.6 \mathrm{~kb}$ der (11) MLL PCR product was only detected in the same bone marrow sample (Figure 3).
This was 4 months after HLH therapy was stopped, and 3 months after the detection of $M L L$ cleavage in the bone marrow.

\section{DISCUSSION}

The occurrence of $\mathrm{t}$-AML involving $M L L$ rearrangements with a latent period of 24-36 months has previously been reported in HLH (Takahashi et al, 1998; Kitazawa et al, 2001). Based on the clinical evidence alone, the latent period from the start of therapy until the diagnosis of overt t-AML in our patient was only 6 months. However, using molecular tracking, we have shown prospectively that etoposide-induced $M L L$ cleavage preceded $M L L$ rearrangement by 3 months, and furthermore, using the panhandle PCR method, that $M L L$ rearrangement could only be detected at the diagnosis of t-AML. As no DNA samples were available to us in the time period between 3 and 6

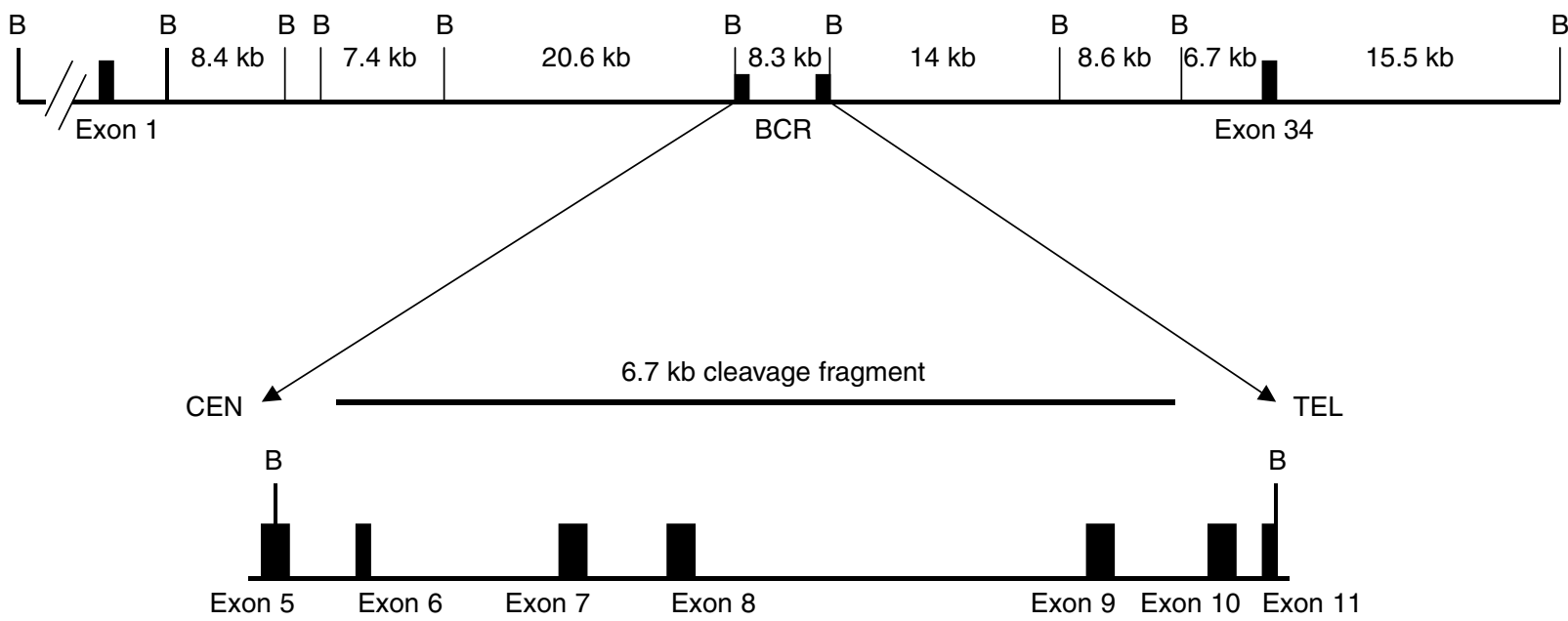

Figure I Human genomic MLL with BCR and MLL cleavage fragment. Schematic representation of the genomic MLL locus with BamHI restriction enzyme sites, the BCR and the etoposide-induced MLL cleavage fragment in this patient. B - BamHI sites.

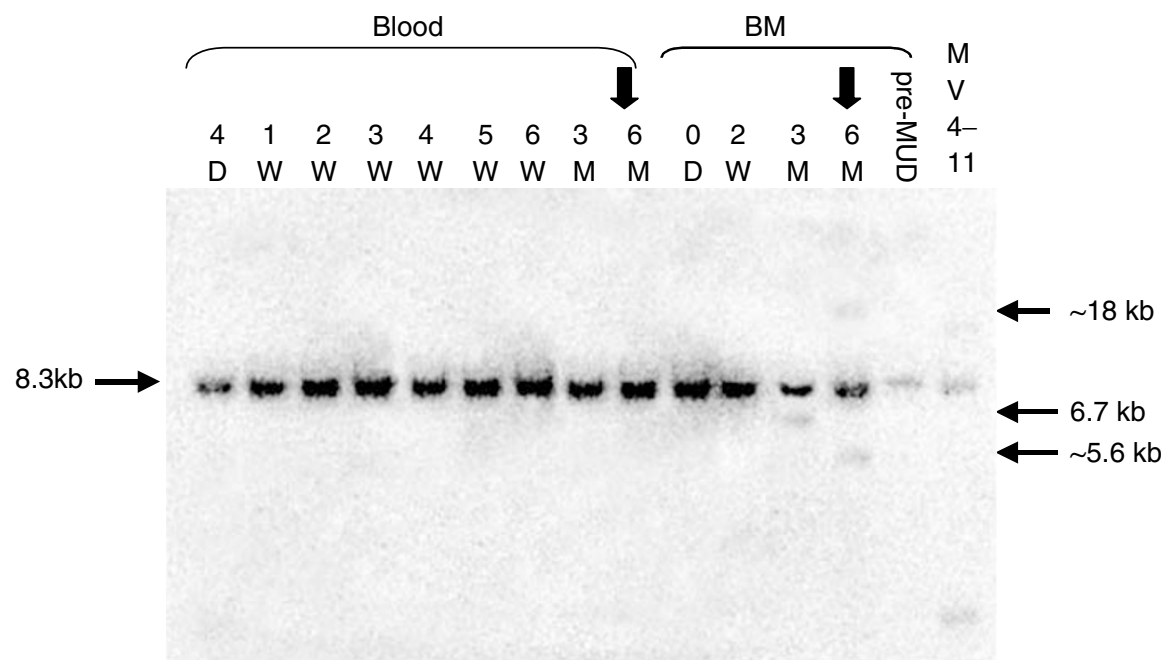

Figure 2 Southern blot analysis of serial samples for MLL cleavage and rearrangement. Instantlmager bitmap showing the detection of ${ }^{32} \mathrm{P}$-labelled $M L L$ probe hybridisation. MLL cleavage fragment $(6.7 \mathrm{~kb})$ was identified in the bone marrow 3 months after the start of etoposide therapy. MLL rearranged fragments $(5.6,18 \mathrm{~kb})$ and germline BCR fragment $(8.3 \mathrm{~kb})$ were only detected at the clinical presentation of $\mathrm{t}-\mathrm{AML}$. MLL rearrangement resolved with further chemotherapy prior to the bone marrow transplant. D - day; W - week; M - month, from the diagnosis of HLH; $\mathbf{I}$ - clinical presentation of t-AML; $\mathrm{BM}$ - bone marrow; MUD - matched, unrelated donor transplant. 


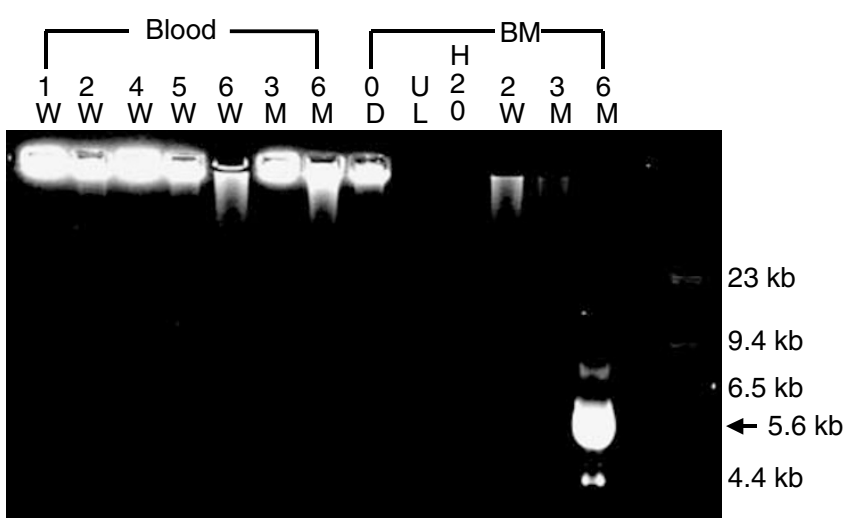

Figure 3 Panhandle PCR on the same samples for the detection of MLL rearrangement. Gel doc image showing the panhandle PCR product $(5.6 \mathrm{~kb})$ after agarose gel electrophoresis. It was only detected in the patient's bone marrow 6 months after the start of etoposide therapy. Negative controls: UL - unligated, $\mathrm{H}_{2} \mathrm{O}$ - water; $\mathrm{BM}$ - bone marrow; $D$ - day; $W$ - week; $M$ - month, from the diagnosis of HLH.

months after HLH diagnosis, our conservative estimate is that the $\mathrm{t}$-AML clone emerged during a period $\leqslant 3$ months. Cytogenetic and provisional sequencing data conclude that the rearrangement

\section{REFERENCES}

Aplan PD, Chervinsky DS, Stanulla M, Burhans WC (1996) Site-specific DNA cleavage within the $M L L$ breakpoint cluster region induced by topoisomerase 2 inhibitors. Blood 87: 2649-2658

Felix CA (1998) Secondary leukaemias induced by topoisomerase-targeted drugs. Biochim Biophys Acta 1400: 233-255

Felix CA, Jones DH (1998) Panhandle PCR: a technical advance to amplify $M L L$ genomic translocation breakpoints. Leukemia 12: 976-981

Henter JI, Arico M, Egeler RM, Elinder G, Favera BE, Filipovich AH, Gadner H, Imashuku S, Janka-Schaub G, Komp D, Ladisch S, Web D (1997) HLH-94: a treatment protocol for hemophagocytic lymphohistiocytosis. Med Pediatr Oncol 28: $342-347$

Kitazawa J, Ito E, Arai K, Yokoyama M, Fukayama M, Imashuku S (2001) Secondary acute myelocytic leukemia after successful chemotherapy with etoposide for Epstein-Barr virus-associated hemophagocytic lymphohistiocytosis. Med Pediatr Oncol 37: 153 - 154

Lovett BD, Nigro LL, Rappaport EF, Blair IA, Osheroff N, Zheng N, Megonigal MD, Williams WR, Nowell PC, Felix CA (2001) Near-precise interchromosomal recombination and functional DNA topoisomerase 2 cleavage sites at $M L L$ and $A F-4$ genomic breakpoints in treatment-related involved $A F 9$ as the partner gene, with nucleotides insertion within the breakpoint junction (intron 6 of $M L L$, intron 4 of $A F 9$ ) of the fusion gene.

Our results differ from those reported by Megonigal et al (2000), who detected a leukaemic clone with MLL-GAS7 within 6 weeks of the start of neuroblastoma therapy including doxorubicin. This was some 15.5 months before the appearance of clinically overt t-AML. The result that we obtained suggests that once established, the putative MLL-AF9 leukaemic clone developed much more rapidly into overt AML as compared to the MLL-GAS7 clone. It also suggests that partner sequences in $M L L$ fusion genes could modify the leukaemogenic process.

As far as we are aware, this is the first case of t-AML in which $M L L$ cleavage and rearrangement have been detected consecutively in a patient developing t-AML. Our finding thus suggests that the two are temporally related, with gene cleavage and DNA processing prior to translocation, as proposed in the work by Lovett et al (2001).

\section{ACKNOWLEDGEMENTS}

We thank Dr Michael J Thirman, University of Chicago, for the $M L L$ probe. acute lymphoblastic leukemia with $\mathrm{t}(4 ; 11)$ translocation. Proc Natl Acad Sci USA 98: $9802-9807$

Megonigal MD, Cheung N-KV, Rappaport EF, Nowell PC, Wilson RB, Jones DH, Addya K, Leonard DGB, Kushner BH, Williams TM, Lange BJ, Felix CA (2000) Detection of leukaemia-associated MLL-GAS7 translocation early during chemotherapy with DNA topoisomerase 2 inhibitors. Proc Natl Acad Sci USA 97: 2814-2819

Pui CH, Relling MV (2002) Topoisomerase 2 inhibitor-related acute myeloid leukaemia. Br J Haematol 109: 13-23

Stevens RF, Hann IM, Wheatley K, Gray RG (1998) Marked improvements in outcome with chemotherapy alone in paediatric acute myeloid leukaemia: results of the United Kingdom Medical Research Council's 10th AML trial. MRC Childhood Leukaemia Working Party. $\mathrm{Br} J$ Haematol 101: $130-140$

Takahashi T, Yagasaki F, Endo K, Takahashi M, Itoh Y, Kawai N, Kusumoto S, Murohashi I, Bessho M, Hirashima K (1998) Therapyrelated AML after successful chemotherapy with low dose etoposide for virus-associated hemophagocytic syndrome. Int J Hematol 68: $333-336$ 